\title{
Treatment Satisfaction and Its Associated Factors of Dolutegravir Based Regimen in a Resource Limited Setting
}

\author{
Eden Abetu Mehari (D) $^{\prime}$ \\ Esileman Abdela Muche (D) \\ Kedir Abdela Gonete ${ }^{2}$ \\ Kirubel Biruk Shiferaw (D) ${ }^{3}$ \\ 'Department of Clinical Pharmacy, \\ School of Pharmacy, College of Medicine \\ and Health Sciences, University of \\ Gondar, Gondar, Ethiopia; ${ }^{2}$ Department \\ of Human Nutrition, Institute of Public \\ Health, College of Medicine and Health \\ Sciences, University of Gondar, Gondar, \\ Ethiopia; ${ }^{3}$ Department of Health \\ Informatics, College of Medicine and \\ Health Sciences, Debre Markos \\ University, Debre Markos, Ethiopia
}

Introduction: Treatment satisfaction is patient's evaluation of the process of taking the medication and its use. Currently dolutegravir based regimen is first-line agent for treatment of human immunodeficiency virus. But evidence is scarce regarding treatment satisfaction. Thus, the aim of the current study was to assess treatment satisfaction and associated factors of dolutegravir based regimen among adult human immunodeficiency virus patients attending at Debre Markos referral 2020.

Methods: Institutional-based cross-sectional study was conducted. A systematic random sampling technique was used to collect data from June 25 to August 25, 2020 at Debre Markos referral hospital. It was entered into Epi Info and exported to SPSS version 23 for analysis. Bivariable and multivariable logistic regression was used to identify factors. Variables with $\mathrm{p}<0.05$ were considered as statistically significant.

Results: From a total of 359, 349 participants (97.2\%) responded to the study. In this study, $70.5 \%$ of participants reported higher treatment satisfaction. Monthly average income of $\geq 3500$ birr (AOR: 2.88; 95\% CI: 1.26, 6.58), 1600-2500 birr (AOR: 2.47; 95\% CI: 1.11, 5.48), 800-1600 birr (AOR: 3.11; 95\% CI: 1.31, 7.37), positive belief about medications (AOR: 3.05; 1.76, 5.28), having a discussion with health care providers (AOR: 3.05, 95\% CI: $1.58,5.88$ ), patients without concurrent medication (AOR: 7.72, 95\% CI: 3.29, 18.07), and being male (AOR: $2.10,95 \% \mathrm{CI}: 1.14,3.87$ ) were associated with treatment satisfaction.

Conclusion: Overall, dolutegravir based regimen showed high treatment satisfaction. Monthly income, positive beliefs about medications, discussing about treatment options, sex and concurrent medications were associated with treatment satisfaction. Thus, it is crucial to improve treatment satisfaction by promoting positive belief towards medication and also by engaging patients in treatment decisions.

Keywords: dolutegravir, treatment satisfaction, Debre Markos

\section{Background}

Treatment satisfaction is a patient-reported outcome (PRO) which is defined as the patient's evaluation of the process of taking the medications and the associated results of its use. ${ }^{1}$ Patient satisfaction concerning their treatment is a predictor of treatment success, the continuance of treatment, the proper use of services, medical adherence, and follow-up with treatment programs. ${ }^{2}$ Moreover, the evidence is scarce regarding treatment satisfaction which hinders actions that would have been taken to evaluate the performance of medications and also not to identify patients who need targeted interventions and predict treatment outcomes. ${ }^{3}$ Currently, integrase strand inhibitors including
Correspondence: Eden Abetu Mehari Tel +251920769917

Email edenabetu@gmail.com 
dolutegravir (DTG) are recommended as first-line core agents for treatment of patients with HIV. ${ }^{4,5}$ The introduction of the integrase strand inhibitor dolutegravir (DTG) offers a great potential for effective and a more durable therapy. ${ }^{6}$ Following this, several countries in sub-Saharan Africa including Ethiopia are in the process of transitioning all first-line regimens to this combination. ${ }^{7}$ Thus, measuring patientreported outcomes such as treatment satisfaction is essential. ${ }^{8}$ Evidence suggests that improved patient satisfaction could increase treatment effectiveness. ${ }^{9}$ In resource limited settings, it is important to ensure quality of care and patient satisfaction in order to make the best use of limited resources. ${ }^{10}$ Levels of treatment satisfaction and associated factors varied across measures, sub-groups of patients, clinical stages, clinics, regions, and health care systems, making it essential to characterize these attributes in each setting. ${ }^{11-13}$ Treatment satisfaction depends on the clinical outcomes achieved such as symptom resolution, control of the disease progression and prevention, the route and ease of drug administration, and drug tolerability. ${ }^{14}$ Thus, treatment satisfaction is an important factor to evaluate in routine clinical practice to help improve and maintain patient well-being. In general, transitioning to new regimen requires careful monitoring of treatment satisfaction of DTG so evidence regarding the new regimen is still needed for low- and middle-income countries.

\section{Method}

\section{Study Setting}

The study was conducted at Debre Markos Referral Hospital, a public center, which is found in Debre Markos town. Debre Markos town is located in East Gojjam Zone of Amhara Nation Regional State. It is situated $299 \mathrm{~km}$ from Addis Ababa, the capital city of Ethiopia. The HIV care in Ethiopia is a uniform service, which is provided in public facilities, and it is a free service. Patients will not be asked payment for HIV diagnosis, follow up or treatment. The hospital provides ART service for about 6350 patients and 5839 of them were adults. Adult patients on dolutegravir based regimen represent $36.8 \%$ of patients cared for in the center. The most common ART regimens other than the dolutegravir based regimen which are delivered in the area include TDF-3TC-EFV, AZT-3TC-EFV, TDF-3TC-NVP and AZT-3TC-NVP.

\section{Study Design and Study Period}

An institutional-based cross-sectional study was employed on adult HIV patients who took a dolutegravir based regimen for six months. Data was collected from June 25 to August 25, 2020. All study participants were treatment experienced individuals who were on a single tablet Tenofovir -Lamivudine and Dolutegravir based regimen (TDF-3TC-DTG).

\section{Sample Size Determination and Procedure}

The sample size was calculated using a single population proportion formula with a $95 \%$ confidence level, the proportion of treatment satisfaction $50 \%$ since there was no previous study done in this study population in Ethiopia and relative precision to be $5 \%$ and it was found to be 384 . The total population of people on dolutegravir based regimen was 2151; since it is less than 10,000 the sample size was reduced by using correction formula and by adding $10 \%$ of non-response rate. The final sample size was calculated to be 359 . The study participants were selected among HIV patients on follow up who visited ART clinic during the data collection period using systematic random sampling by using their medical record order. Then each selected patient was accessed on their waiting area. If the patient was not available the next immediate medical record was selected and the sampling fraction was added to get the next patient. Identification number was given for each medical record to avoid duplication.

\section{Data Collection Instrument and Procedure}

Data was collected by using interviewer administered adopted questionnaires from June 25 to August 25, 2020 by four trained data collectors by maintaining physical distancing and by taking appropriate preventive methods to prevent Covid-19. The questionnaire has seven parts. The first section contains questions about participant's socio-demographic characteristics. The second section is about clinical and treatment related factors. The third one was about knowledge on ART (anti-retroviral therapy) medications.

The questionnaire had twenty-one questions to assess respondents' knowledge about ART medication. One point was allocated for each correct response, otherwise zero was given and negatively worded questions were reverse coded. $^{15}$ The fourth section is composed of questions about beliefs about medications (BMQ). The BMQ consists of two domains and there are five-item scales assessing patients' beliefs about the necessity of prescribed 
medication for treating their disease and their concerns about potential adverse consequences of taking it. Respondents indicate their degree of agreement with each statement on a five-point likert scale, ranging from $1=$ strongly disagree to $5=$ strongly agree. Scores obtained for individual items within both scales were summed. Thus, total scores for the Necessity and Concerns Scales range from 5 to 25. Higher scores indicate stronger beliefs. ${ }^{16}$ The fifth part is treatment satisfaction questionnaire which is the outcome measure. The treatment satisfaction questionnaire for medication version II (TSQM II) consists of eleven items representing four scales: Effectiveness (2 items), Side Effects (4 items), Convenience (3 items), and Global Satisfaction ( 2 items). A validated tool was used to assess treatment Satisfaction with DTG based regimen which was developed by Atkinson et al, Experiences of treatment satisfaction were rated on five-point and seven-point Likert scales from "Extremely dissatisfied" to "Extremely satisfied," with scale scores being converted to a score between 0 and 100 , where higher scores indicate greater satisfaction with treatment. All items of a scale should be filled in order for the scale to be calculated, except for the side effects and convenience scales, for which up to one item each could be missing. ${ }^{17}$ The sixth part is about self-rated health status which was measured with the question "In general, how would you describe your current health?" with "excellent," "very good," "good," "fair" and "poor" responses. ${ }^{18}$ The questionnaire ends with asking about their discussion with health care providers about the treatment switch.

\section{Data Quality and Assurance}

Training was delivered to data collectors on data handling and participants' approach and those data collectors were subject to supervision by a supervisor. The data collection tools were initially prepared in English, translated into Amharic (local language) by language expertise for data collection and re-translated to English to check consistency in meaning of words and concepts. It was pretested on $5 \%$ of the total population at Felege Hiwot comprehensive and specialized hospital. The reliability of the translated tools was assessed with cronbach's alpha coefficient of 0.98 for knowledge about ART medications, 0.77 for beliefs about medicines and 0.88 for TSQM, respectively.

Daily close supervision was done during the time of data collection. The collected data was entered into Epi-Info 7.

\section{Data Processing and Analysis}

Descriptive analysis was performed to summarize participants' characteristics. Multi-collinearity was tested and the result showed all the variance inflation factor (VIF) value less than three and tolerance less than ten which demonstrated the absence of multicollinearity. ${ }^{19}$ Outshining outlier effect was not observed in the box plot. The omnibus test result was significant with $\mathrm{p}$-value $<0.05$ and the Hosmer and Lemeshow test showed a good model fit with $p$-value $>0.05$, which signifies the goodness fit of the model. ${ }^{20} \mathrm{~A}$ logistic regression was performed for each independent variable and a $\mathrm{p}$-value $<0.2$ was included in the final model. Multivariable logistic regression was fitted to identify significant factors (P-value $<0.05$ ) associated with treatment satisfaction.

For beliefs about medicines, the perceptions of cost (concerns) are weighed against their perception of benefit (necessity beliefs). If the difference is positive, the patient perceives that the benefits of medication outweigh the costs and categorized as having positive belief. Conversely, if it is negative, the patient perceives greater cost than benefit and categorized as having negative belief. ${ }^{16}$ For knowledge about medicines, respondents who scored the median and above of 21 knowledge questions were considered to have good knowledge; while those who scored below the median were considered as having poor knowledge about ART medications. ${ }^{15}$ Viral load was dichotomized and Virological suppression was defined as a plasma viral load of less than 50 copies $/ \mathrm{mL}$ as determined with the Food and Drug Administration Snapshot algorithm. ${ }^{21}$

Global treatment satisfaction was skewed and measured by eleven questions and scores greater than a median score were considered to have higher treatment satisfaction; while those who scored below the median were considered as having lower treatment satisfaction. ${ }^{17}$

\section{Ethics Approval and Consent to Participate}

Ethical clearance was obtained from the Ethical Review Committee of School of Pharmacy, University of Gondar. Necessary permission was gained from the Debre Markos referral hospital. The study was conducted according to the criteria set by the declaration of Helsinki. The respondents were informed about the purpose of the study and their consent to participate was obtained. Data were collected after written informed consent was obtained and confidentiality of the information was maintained. 


\section{Result}

\section{Socio-Demographic Characteristics}

In this study 359 patients were approached and 349 patients who were on a single tablet TDF-3TC-DTG agreed to take part, giving a response rate of $97.2 \%$. The mean age of the participants was 40.28 years \pm 11.6 and $192(55.0 \%)$ of them were female. Majority of the participants 297 (85.1\%) were urban dwellers and 98 (28.1\%) participants had a monthly income of $\geq 3500$ birr. Of all the study participants, 109 (31.2\%) had primary school education. The mean duration on ART was $8.3 \pm 3.6$ years (Table 1 ).

\section{Clinical and Knowledge Factors}

Majority of the participants, 266 (76.22\%), had a good knowledge towards ART medication. Among the study participants, 321 (92\%) maintained virological suppression.

Positive belief was reported in $182(52.1 \%)$ participants and half of the participants, $178(51.0 \%)$, rated their health as good. Among comorbidities, hypertension was seen in 14 (4\%) participants and hydrochlorothiazide was prescribed for $8(21.6 \%)$ participants (Table 2).

Table I Descriptive Statistics of Socio-Demographic Characteristics of HIV Patients on Dolutegravir Based Regimen at Debre Markos Referral Hospital 2020

\begin{tabular}{|c|c|c|c|c|c|}
\hline Variable & $\mathbf{N}$ & $\%$ & Variable & $\mathbf{N}$ & $\%$ \\
\hline \multicolumn{3}{|l|}{ Age } & \multicolumn{3}{|l|}{ Monthly Income } \\
\hline$|9-3|$ & 94 & 26.9 & $<800$ & 71 & 20.3 \\
\hline $32-44$ & 129 & 37.0 & $800-1600$ & 95 & 27.2 \\
\hline $45-57$ & 102 & 29.2 & $1600-3500$ & 85 & 24.4 \\
\hline $58-70$ & 19 & 5.4 & $\geq 3500$ & 98 & 28.1 \\
\hline $7 \mid-83$ & 5 & 1.4 & \multicolumn{3}{|l|}{ Marital status } \\
\hline \multicolumn{3}{|l|}{ Sex } & Single & 64 & 18.3 \\
\hline Female & 192 & 55.0 & Married & 155 & 44.4 \\
\hline Male & 157 & 45.0 & Divorced & 65 & 18.6 \\
\hline \multicolumn{3}{|l|}{ Residency } & Widowed & 65 & 18.6 \\
\hline Urban & 297 & 85.1 & \multicolumn{3}{|l|}{ Educational status } \\
\hline \multirow[t]{3}{*}{ Rural } & 52 & 14.9 & No formal education & 70 & 20.1 \\
\hline & & & Primary school Education & 109 & 31.2 \\
\hline & & & Secondary school education & 95 & 27.2 \\
\hline \multicolumn{3}{|c|}{ Occupational status } & Diploma and above & 75 & 21.5 \\
\hline Unemployed & 62 & 17.8 & \multicolumn{3}{|l|}{ Religion } \\
\hline Governmental & 109 & 31.2 & Orthodox & 228 & 65.3 \\
\hline jobs & & & Muslim & 118 & 33.8 \\
\hline Private jobs & 178 & 51.0 & Protestant & 3 & 0.9 \\
\hline
\end{tabular}

\section{Level of Treatment Satisfaction}

In this study $70.5 \%$ (95\% CI $65.7,75.3)$ of the participants reported high treatment satisfaction. The median effectiveness score was 83.3 (IQR 75,100), with the highest individual dimension score being observed for the side effects dimension, 91.7 (IQR 83.33, 100), the median convenience score was 83.3 (IQR 77.77, 100) and the median global satisfaction score was 83.3 (IQR 75,100). A Spearman correlation was done between each domain of TSQM and the overall satisfaction score due to the non-normality of the data.

The test revealed a significantly strong positive correlation between overall treatment satisfaction score and effectiveness domain $\left(r_{s}=0.63 ; p<0.001\right)$, overall treatment satisfaction score and convenience domain $(r s=0.65 ; p<0.001)$.

\section{Factors Associated with Treatment Satisfaction of Dolutegravir Based Regimen}

In the bivariate logistic regression analysis, it is illustrated that occupation, average monthly income, sex, beliefs about medications, concurrent medications and discussion with healthcare providers about the treatment change were significantly associated with treatment satisfaction of dolutegravir based regimen. However, in multivariable logistic regression analysis, average monthly income, beliefs about medications, concurrent medications, sex and discussion with health care providers about the treatment change remained significantly associated with treatment satisfaction of dolutegravir based regimen.

Accordingly, participants with an average monthly income of $\geq 3500,1600-3500$ and $800-1600$ birr had 3.11 times (AOR: 3.11; 95\% CI: 1.31, 7.37), 2.47 times (AOR: 2.47; 95\% CI: 1.11, 5.48) and 2.88 times (AOR: 2.88; 95\% CI: $1.26,6.58$ ) higher odds of being satisfied with dolutegravir based regimen, respectively, than those with an average monthly income of $\leq 800$ birr.

Participants who had positive beliefs towards their medication had the odds of 3.05 times (AOR: 3.05; 1.76, 5.28) more likely being satisfied with dolutegravir based regimen compared to those who had negative beliefs towards their medication.

Similarly, this study revealed that those participants without concurrent medication with dolutegravir based regimen had 7.72 times (AOR: 7.72, 95\% CI: 3.29, 18.07) higher odds of treatment satisfaction compared to those with concurrent medication. Besides, the odds of 
Table 2 Descriptive Statistics of Clinical Characteristics and Knowledge of HIV Patients on Dolutegravir Based Regimen at Debre Markos Referral Hospital 2020

\begin{tabular}{|c|c|c|c|c|c|}
\hline & $\mathbf{N}$ & $\%$ & Self-Rated Health Status & $\mathbf{N}$ & $\%$ \\
\hline Beliefs about medications & & & Poor & 9 & 2.6 \\
\hline Positive belief & 182 & 52.1 & Fair & 154 & 44.1 \\
\hline Negative belief & 167 & 47.9 & Good & 178 & 51.0 \\
\hline Knowledge about medications & & & Excellent & 8 & 2.3 \\
\hline Good & 266 & 76.22 & Concurrent medications with DTG & \multicolumn{2}{|c|}{$\mathbf{N}=\mathbf{3 7}$} \\
\hline Poor & 83 & 23.78 & Isoniazid & 7 & 18.9 \\
\hline Comorbidity & & & Hydrochlorothiazide & 8 & 21.6 \\
\hline None & 312 & 89.4 & Nifedipine & 4 & 10.8 \\
\hline Hypertension & 14 & 4 & Metformin & 4 & 10.8 \\
\hline Tuberculosis & 7 & 2 & Insulin & 3 & 8.1 \\
\hline Diabetes & 7 & 2 & Others*** & II & 29.8 \\
\hline Meningitis & 2 & 0.6 & & & \\
\hline Others** & 7 & 2 & & & \\
\hline
\end{tabular}

Notes: **Pneumonia, PUD, toxoplasmosis, PCP, oral candidiasis. ***Others: amoxicillin and clavulanate potassium, metronidazole, tramadol, cotrimoxazole, cimetidine, omeprazole, fluconazole, pyridoxine, enalapril, ceftriaxone.

higher treatment satisfaction among participants who had communicated with health care providers about the treatment change was 3.05 times (AOR: 3.05 , 95\% CI: 1.58 , 5.88) higher compared to those without communication with health care providers. On the other hand, the odds of high treatment satisfaction was 2.10 times (AOR: 2.10, CI: $1.14,3.87$ ) higher among males as compared to females (Table 3 ).

\section{Discussion}

In this study, $70.5 \%$ (95\% CI $65.7,75.3)$ of participants reported high treatment satisfaction with higher scores in each domain of treatment satisfaction, among participants on dolutegravir based regimen. The median score was $83.3 \%, 91.7 \%, 100 \%, 83.3 \%$, and $83.3 \%$ in effectiveness, side effects, convenience, and global satisfaction domains. This result agrees with other studies, ${ }^{22,23}$ which reported high treatment satisfaction with dolutegravir based regimen. This higher treatment satisfaction with dolutegravir based regimen could be due to the reason that dolutegravir based regimen is more effective, ${ }^{24}$ easier to use, and has fewer side effects ${ }^{25}$ than alternative drugs that are currently used. This can also partially be explained by the fact that dolutegravir reduces pill burden and its simplification which allows once-daily administration, ${ }^{26}$ which in turn increases treatment satisfaction.

This study also revealed that participants who had communicated with the health care providers about the treatment change were more satisfied than those participants who did not communicate about the treatment change. This could be due to the fact that having enough information about the drug patients are using enhances their trust and hence satisfaction. In addition, the quality of the patient/health care provider relationship influences their treatment satisfaction and adherence. ${ }^{27-32}$ This finding is also consistent with those of previous studies demonstrating the important role that clinicians play in treatment satisfaction, and emphasizes the potential benefit of clinician-patient dialogue in optimizing patient satisfaction to treatment. ${ }^{28,30}$

Another significant association found in this study was patients' beliefs towards medications and treatment satisfaction. Those participants who had positive beliefs towards medication were more likely to be satisfied with their medication than participants with negative beliefs. Participants with negative belief had lower satisfaction than those with positive belief. This might be due to the reason that medication use behavior is impacted by 
Table 3 Factors Associated with Treatment Satisfaction of Dolutegravir Based Regimen at DRH 2020

\begin{tabular}{|c|c|c|c|c|c|c|}
\hline \multirow{4}{*}{$\begin{array}{l}\text { Independent Variable } \\
\text { Gender } \\
\text { Male } \\
\text { Female }\end{array}$} & \multicolumn{2}{|c|}{ Treatment Satisfaction } & \multirow{4}{*}{$\begin{array}{l}\operatorname{COR}(\mathrm{CI}) \\
\begin{array}{l}3.37(2.03,5.62) \\
\mathrm{I}\end{array}\end{array}$} & \multirow{4}{*}{$\begin{array}{l}\text { P-value } \\
<0.001\end{array}$} & \multirow{4}{*}{$\begin{array}{l}\operatorname{AOR}(\mathrm{CI}) \\
2.10(1.14,3.87) \\
1\end{array}$} & \multirow{4}{*}{$\begin{array}{l}\text { P-value } \\
0.017^{*}\end{array}$} \\
\hline & High & Low & & & & \\
\hline & $13 \mid$ & 26 & & & & \\
\hline & 115 & 77 & & & & \\
\hline Occupation Type & & & & 0.053 & & 0.084 \\
\hline Governmental job & 68 & 41 & $0.73(0.38,1.42)$ & 0.359 & $0.44(0.18,1.05)$ & 0.065 \\
\hline Privet job & 135 & 43 & $1.39(0.73,2.63)$ & 0.190 & $0.83(0.39,1.80)$ & 0.643 \\
\hline Unemployed & 43 & 19 & 1 & & I & \\
\hline \multicolumn{7}{|l|}{ Do you discuss about the treatment change? } \\
\hline Yes & 114 & 21 & $3.37(1.96,5.79)$ & $<0.001$ & $3.03(1.58,5.88)$ & $0.00 I^{*}$ \\
\hline No & 132 & 82 & 1 & & I & \\
\hline Monthly income & & & & & & $0.039 *$ \\
\hline$<800$ & 41 & 30 & I & 0.065 & I & \\
\hline $800-1600$ & 72 & 23 & $2.29(1.18,4.45)$ & 0.015 & $2.88(1.26,6.58)$ & $0.012^{*}$ \\
\hline $1600-2500$ & 63 & 22 & $2.10(1.07,4.12)$ & 0.032 & $2.47(I .1 I, 5.48)$ & $0.026^{*}$ \\
\hline$\geq 3500$ & 70 & 28 & $1.83(0.96,3.48)$ & 0.066 & $3.11(1.31,7.37)$ & $0.010^{*}$ \\
\hline \multicolumn{7}{|l|}{ Beliefs about medication } \\
\hline Positive belief & 146 & 36 & $2.72(1.68,4.38)$ & $<0.001$ & $3.05(1.76,5.28)$ & $0.0001 *$ \\
\hline Negative belief & 100 & 67 & I & & I & \\
\hline \multicolumn{7}{|l|}{ Concurrent medications } \\
\hline No & 232 & 80 & $4.76(2.34,9.70)$ & $<0.001$ & $7.72(3.29,18.07)$ & $0.0001 *$ \\
\hline Yes & 14 & 23 & I & & I & \\
\hline
\end{tabular}

Note: *Significant at $\mathrm{p}<0.05$.

patients' perceptions about the benefits of taking such medication. $^{33}$ Thus negative belief towards ART has been associated with a higher likelihood of nonadherence $^{34}$ and dropping out of care both in highincome settings ${ }^{35-37}$ and in sub-Saharan Africa. ${ }^{38-40}$ In addition, they tend to have suboptimal adherence which leads to inadequate viral suppression and the emergence of drug-resistant strains of $\mathrm{HIV}-1,{ }^{41}$ resulting in treatment failure, disease progression, and the potential for transmission of resistant virus which are a major obstacle to the long-term efficacy of ART. ${ }^{42-45}$ This in turn might lower level of treatment satisfaction.

Income was the other significant factor associated with treatment satisfaction. Those participants who had monthly income $>3500$ ETB are more likely to have higher treatment satisfaction compared to those who earn monthly income $<800$ ETB. This lends weight to the concept that lower income is associated with lower treatment satisfaction. Even though Ethiopia has universal free access to health care, including HIV diagnosis, hospital consultations, and antiretroviral treatment, income was found to be a significant predictor of treatment satisfaction. This is because the adverse implications of poorer socioeconomic status clearly go beyond inability to pay for treatment and health care, and operate strongly even in people engaged with clinical care. ${ }^{46}$

There are a number of reasons why people with lower income might have greater difficulties maintaining treatment adherence which might lead to lower treatment satisfaction, including competing responsibilities and stress, unsettled living circumstances, food insecurity, ${ }^{47}$ increased prevalence of mental health problems, ${ }^{48}$ stigma and low self-esteem, ${ }^{49}$ and altered pharmacokinetics through absence of sufficient food. ${ }^{50}$

On the other hand, taking concurrent medication was negatively associated with treatment satisfaction in this study. This can be evidenced by a Swiss cohort study that revealed a significantly increased chance of potentially serious drug-drug interactions with concurrent medication use, ${ }^{51}$ which in turn is associated with lower treatment satisfaction. Complexity is one of the main causes of treatment dissatisfaction. Currently, the complexity of the antiretroviral regimen has decreased, but HIV patients also have a greater number of prescription drugs for other diseases which may limit adherence and 
therapeutic success which leads to lower treatment satisfaction due to treatment failure as a result of non adherence which is caused by complexity and pill burden. ${ }^{52-55}$ On the other hand male participants tend to have high treatment satisfaction as compared to female participants.

The limitation behind this study is being a crosssectional study with a single-arm; no conclusions can be drawn whether satisfaction is with dolutegravir-based therapies or with antiretroviral treatment in general. Moreover, treatment naïve participants were not included. In addition, this study was a hospital-based study in which those subjects who did not come to the hospital were not included and it would be better if future research could be done by addressing the above mentioned limitations.

\section{Conclusion}

This study identified that, dolutegravir based regimen resulted a high treatment satisfaction among treatmentexperienced HIV patients. Higher monthly income, positive belief towards medication and communication about treatment change were positively associated with treatment satisfaction whereas concurrent medications were negatively associated with treatment satisfaction.

\section{Recommendations}

It would be better if communication was carried out between patients and health professionals about the treatment change as communication about the treatment change predicted treatment satisfaction. The limitation behind this study is its lack to generalize the findings to treatment naïve participants. Therefore, future research shall be conducted on treatment naïve HIV patients on dolutegravir based regimen as well as treatment satisfaction after longer duration of therapy could be considered for future research.

\section{Abbreviations}

ART, Antiretroviral therapy; BMQ, Beliefs about Medicines Questionnaire; DRH, Debre Markos Referral Hospital; Epi Info, Epidemiological Information; ETB, Ethiopian Birr; HIV, Human immune deficiency virus; TSQM II, Treatment Satisfaction Questionnaire for Medication version II.

\section{Data Sharing Statement}

The datasets during and/or analyzed during the current study are available from the corresponding author upon request.

\section{Ethics Approval and Consent to Participate}

Ethical clearance was obtained from the Ethical Review Committee of School of Pharmacy, University of Gondar. Necessary permission was gained from the Debre Markos referral hospital. The study was conducted according to the criteria set by the declaration of Helsinki. The respondents were informed about the purpose of the study and their consent to participate was obtained. Data were collected after written informed consent was obtained and confidentiality of the information was maintained.

\section{Consent to Publish}

Participants' consent was taken to publish this work.

\section{Acknowledgments}

We would like to acknowledge the University of Gondar for funding this research project. We are also thankful to study participants, to data collectors and supervisor for their contribution in this research.

\section{Author Contributions}

All authors made substantial contributions to conception and design, acquisition of data, or analysis and interpretation of data; took part in drafting the article and revising it critically for important intellectual content; agreed to submit to the current journal; gave final approval of the version to be published; and agree to be accountable for all aspects of the work.

\section{Funding}

This research was done with the financial support of University of Gondar. The funding offices had no direct or indirect involvement in the study write up and analysis.

\section{Disclosure}

The authors declare that they have no conflict of interest.

\section{References}

1. Langerman H, Gadsby R. Treatment satisfaction: a neglected but important outcome measure in older people with type 2 diabetes. J Ageing Res Clin Pract. 2017;6:124-132.

2. Sweileh WM, Ihbesheh MS, Jarar IS, et al. Self-reported medication adherence and treatment satisfaction in patients with epilepsy. Epilep Behav. 2011;21(3):301-305. doi:10.1016/j.yebeh.2011.04.011

3. Mayberry RM, Nicewander DA, Qin H, Ballard DJ. Improving quality and reducing inequities: a challenge in achieving best care. World Hosp Health Serv. 2008;44(3):16-31. 
4. World Health Organization. Update of Recommendations on Firstand Second-line Antiretroviral Regimens. World Health Organization; 2019.

5. Ryom L, Cotter A, De Miguel R, et al. 2019 update of the European AIDS clinical society guidelines for treatment of people living with HIV version 10.0. HIV Med. 2020;21(10):617-624. doi:10.1111/ hiv. 12878

6. Walmsley S, Baumgarten A, Berenguer J, et al. Brief report: dolutegravir plus abacavir/lamivudine for the treatment of HIV-1 infection in antiretroviral therapy-naive patients: week 96 and week 144 results from the SINGLE randomized clinical trial. JAIDS. 2015;70(5):515. doi:10.1097/QAI.0000000000000790

7. Group NAS. Dolutegravir-based or low-dose Efavirenz-based regimen for the treatment of HIV-1. N Engl J Med. 2019;381(9):816-826. doi:10.1056/NEJMoa1904340

8. Weldring T, Smith SM. Article commentary: patient-reported outcomes (pros) and patient-reported outcome measures (PROMs). Health Serv Insights. 2013;6:S11093. doi:10.4137/HSI.S11093

9. Walters-Salas E. The challenge of patient adherence. Bariatric Nur Surg Patient Care. 2012;7(4):186. doi:10.1089/bar.2012.9960

10. Mosadeghrad AM. Factors affecting medical service quality. Iran J Public Health. 2014;43(2):210.

11. Vo BN, Cohen CR, Smith RM, et al. Patient satisfaction with integrated HIV and antenatal care services in rural Kenya. AIDS Care. 2012;24(11):1442-1447. doi:10.1080/09540121.2011.652357

12. Njilele A, Ukwe C, Okonta J, Ekwunife O. Development of a patient satisfaction questionnaire for HIV/AIDS patients in Nigeria. Int J Clin Pharm. 2012;34(1):98-104. doi:10.1007/s11096-011-9596-9

13. Devnani M, Gupta AK, Wanchu A, Sharma RK. Factors associated with health service satisfaction among people living with HIV/AIDS: a cross sectional study at ART center in Chandigarh, India. AIDS Care. 2012;24(1):100-107. doi:10.1080/09540121.2011.592816

14. Willke RJ. Measuring the value of treatment to patients: patient-reported outcomes in drug development. Am Health Drug Benefits. 2008;1(1):34.

15. Balfour L, Kowal J, Tasca G, et al. Development and psychometric validation of the HIV treatment knowledge scale. AIDS Care. 2007;19(9):1141-1148. doi:10.1080/09540120701352241

16. Horne R, Weinman J. Patients' beliefs about prescribed medicines and their role in adherence to treatment in chronic physical illness. J Psychosom Res. 1999;47(6):555-567. doi:10.1016/S0022-3999(99)00057-4

17. Atkinson MJ, Kumar R, Cappelleri JC, Hass SL. Hierarchical Construct Validity of the Treatment Satisfaction Questionnaire for Medication (TSQM Version II) Among Outpatient Pharmacy Consumers. Elsevier; 2005.

18. Zajacova A, Dowd JB. Reliability of self-rated health in US adults. Am J Epidemiol. 2011;174(8):977-983. doi:10.1093/aje/kwr204

19. O'brien RM. A caution regarding rules of thumb for variance inflation factors. Qual Quant. 2007;41(5):673-690. doi:10.1007/s11135006-9018-6

20. Hosmer DW, Lemeshow S, Sturdivant RX. Applied Logistic Regression. John Wiley \& Sons; 2013.

21. Evaluation FD. Human immunodeficiency virus-1 infection: developing antiretroviral drugs for treatment. Guidance for industry. 2015.

22. Oglesby A, Punekar A, Angelis K, et al. Patient reported outcomes after switching to a 2 drug regimen of dolutegravir+ rilpivirine: results from the SWORD-1 and SWORD-2 studies. 16th European AIDS conference; 2017.

23. Trottier B, Lake JE, Logue K, et al. Dolutegravir/abacavir/lamivudine versus current ART in virally suppressed patients (STRIIVING): a 48-week, randomized, non-inferiority, open-label, phase IIIb study. Antivir Ther. 2017;22(4):295-305. doi:10.3851/IMP3166

24. Mondi A, Cozzi-Lepri A, Tavelli A, et al. Effectiveness of dolutegravir-based regimens as either first-line or switch antiretroviral therapy: data from the Icona cohort. $J$ Int AIDS Soc. 2019;22(1): e25227. doi:10.1002/jia2.25227
25. Del Mar Gutierrez M, Mateo MG, Vidal F, Domingo P. Drug safety profile of integrase strand transfer inhibitors. Expert Opin Drug Saf. 2014;13(4):431-445. doi:10.1517/14740338.2014.897327

26. Dolutegravir W. And the Fixed Dose Combination (FDC) of Tenofovir/Lamivudine/dolutegravir (TLD). Geneva: World Health Organisation; 2018.

27. Catz SL, Kelly JA, Bogart LM, Benotsch EG, McAuliffe TL. Patterns, correlates, and barriers to medication adherence among persons prescribed new treatments for HIV disease. Health Psychol. 2000;19(2):124. doi:10.1037/0278-6133.19.2.124

28. Katz IT, Ryu AE, Onuegbu AG, et al. Impact of HIV-related stigma on treatment adherence: systematic review and meta-synthesis. $J$ Int AIDS Soc. 2013;16:18640. doi:10.7448/IAS.16.3.18640

29. Ingersoll KS, Heckman CJ. Patient-clinician relationships and treatment system effects on HIV medication adherence. AIDS Behav. 2005;9(1):89-101. doi:10.1007/s10461-005-1684-1

30. Flickinger TE, Saha S, Moore RD, Beach MC. Higher quality communication and relationships are associated with improved patient engagement in HIV care. JAIDS. 2013;63(3):362. doi:10.1097/ QAI.0b013e318295b86a

31. Kalichman SC, Pope H, White D, et al. Association between health literacy and HIV treatment adherence: further evidence from objectively measured medication adherence. J Int Assoc Physicians AIDS Care. 2008;7(6):317-323. doi:10.1177/1545109708328130

32. Kremer H, Ironson G, Porr M. Spiritual and mind-body beliefs as barriers and motivators to HIV-treatment decision-making and medication adherence? A qualitative study. AIDS Patient Care STDS. 2009;23(2):127-134. doi:10.1089/apc.2008.0131

33. Adefolalu A, Nkosi Z, Olorunju S, Masemola P. Self-efficacy, medication beliefs and adherence to antiretroviral therapy by patients attending a health facility in Pretoria. South Afr Fam Pract. 2014;56(5):281-285. doi:10.1080/20786190.2014.975476

34. Langebeek N, Gisolf EH, Reiss P, et al. Predictors and correlates of adherence to combination antiretroviral therapy (ART) for chronic HIV infection: a meta-analysis. BMC Med. 2014;12(1):1-14.

35. Godin G, Cote J, Naccache H, Lambert L-D, Trottier S. Prediction of adherence to antiretroviral therapy: a one-year longitudinal study. AIDS Care. 2005;17(4):493-504. doi:10.1080/09540120412331291715

36. Grierson J, Koelmeyer R, Smith A, Pitts M. Adherence to antiretroviral therapy: factors independently associated with reported difficulty taking antiretroviral therapy in a national sample of HIV-positive Australians. HIV Med. 2011;12(9):562-569. doi:10.1111/j.1468-1293.2011.00928.x

37. Kerr T, Palepu A, Barness G, et al. Psychosocial determinants of adherence to highly active antiretroviral therapy among injection drug users in Vancouver. Antiviral Ther. 2004;9(3):407-414.

38. Boateng D, Kwapong GD, Agyei-Baffour P. Knowledge, perception about antiretroviral therapy (ART) and prevention of mother-to-childtransmission (PMTCT) and adherence to ART among HIV positive women in the Ashanti Region, Ghana: a cross-sectional study. BMC Womens Health. 2013;13(1):1-8. doi:10.1186/1472-6874-13-2

39. Gourlay A, Birdthistle I, Mburu G, Iorpenda K, Wringe A. Barriers and facilitating factors to the uptake of antiretroviral drugs for prevention of mother-to-child transmission of HIV in sub-Saharan Africa: a systematic review. J Int AIDS Soc. 2013;16(1):18588. doi:10.7448/IAS.16.1.18588

40. Lifson AR, Demissie W, Tadesse A, et al. Barriers to retention in care as perceived by persons living with HIV in rural Ethiopia: focus group results and recommended strategies. JIAPAC. 2013;12 (1):32-38. doi:10.1177/1545109712456428

41. Kuritzkes DR. Preventing and managing antiretroviral drug resistance. AIDS Patient Care STDs. 2004;18(5):259-273. doi: $10.1089 / 108729104323076007$

42. Press N, Tyndall MW, Wood E, Hogg RS, Montaner J. Virologic and immunologic response, clinical progression, and highly active antiretroviral therapy adherence. JAIDS. 2002;31:S112-7. doi:10.1097/ 00126334-200212153-00005 
43. Bangsberg DR, Hecht FM, Charlebois ED, et al. Adherence to protease inhibitors, HIV-1 viral load, and development of drug resistance in an indigent population. Aids. 2000;14(4):357-366. doi:10.1097/00002030-200003100-00008

44. Little SJ, Holte S, Routy J-P, et al. Antiretroviral-drug resistance among patients recently infected with HIV. $N$ Engl J Med. 2002;347(6):385-394. doi:10.1056/NEJMoa013552

45. Paterson DL, Swindells S, Mohr J, et al. Adherence to protease inhibitor therapy and outcomes in patients with HIV infection. Ann Intern Med. 2000;133(1):21-30. doi:10.7326/0003-4819-1331-200007040-00004

46. Burch LS, Smith CJ, Anderson J, et al. Socioeconomic status and treatment outcomes for individuals with HIV on antiretroviral treatment in the UK: cross-sectional and longitudinal analyses. Lancet Public Health. 2016;1(1):e26-e36. doi:10.1016/S2468-2667(16) 30002-0

47. Kalichman SC, Washington C, Grebler T, et al. Medication adherence and health outcomes of people living with HIV who are food insecure and prescribed antiretrovirals that should be taken with food. Infect Dis Ther. 2015;4(1):79-91. doi:10.1007/s40121-015-0057-y

48. Moralejo L, Inés S, Marcos M, Fuertes A, Luna G. Factors influencing adherence to highly active antiretroviral therapy in Spain. Curr HIV Res. 2006;4(2):221-227. doi:10.2174/157016206776055075

49. Goldman DP, Smith JP. Can patient self-management help explain the SES health gradient? Proc Natl Acad Sci. 2002;99(16):10929-10934. doi:10.1073/pnas.162086599
50. Weiser SD, Frongillo EA, Ragland K, Hogg RS, Riley ED, Bangsberg DR. Food insecurity is associated with incomplete HIV RNA suppression among homeless and marginally housed HIV-infected individuals in San Francisco. $J$ Gen Intern Med. 2009;24(1):14-20. doi:10.1007/s11606-008-0824-5

51. Marzolini C, Back D, Weber R, et al. Ageing with HIV: medication use and risk for potential drug-drug interactions. J Antimicrob Chemother. 2011;66(9):2107-2111. doi:10.1093/jac/dkr248

52. Cantudo-Cuenca MR, Jiménez-Galán R, Almeida-González CV, Morillo-Verdugo R. Concurrent use of comedications reduces adherence to antiretroviral therapy among HIV-infected patients. J Manag Care Pharm. 2014;20(8):844-850. doi:10.18553/jmcp.2014.20.8.844

53. García de Olalla P, Knobel H, Carmona A, Guelar A, LópezColomés JL, Caylà JA. Impact of adherence and highly active antiretroviral therapy on survival in HIV-infected patients. AIDS. 2002;30(1):105-110.

54. Lima VD, Harrigan R, Bangsberg DR, et al. The combined effect of modern highly active antiretroviral therapy regimens and adherence on mortality over time. JAIDS. 2009;50(5):529. doi:10.1097/ QAI.0b013e31819675e9

55. Nieuwkerk PT, Oort FJ. Self-reported adherence to antiretroviral therapy for HIV-1 infection and virologic treatment response: a meta-analysis. JAIDS. 2005;38(4):445-448. doi:10.1097/01. qai.0000147522.34369.12
Patient Preference and Adherence

\section{Publish your work in this journal}

Patient Preference and Adherence is an international, peer-reviewed, open access journal that focusing on the growing importance of patient preference and adherence throughout the therapeutic continuum. Patient satisfaction, acceptability, quality of life, compliance, persistence and their role in developing new therapeutic modalities and compounds to optimize clinical outcomes for existing disease states are major areas of interest for the journal. This journal has been accepted for indexing on PubMed Central. The manuscript management system is completely online and includes a very quick and fair peer-review system, which is all easy to use. Visit http:// www.dovepress.com/testimonials.php to read real quotes from published authors. 